\title{
ESTRATIGRAFIA E SEDIMENTOLOGIA DO PROTEROZÓICO MÉDIO E SUPERIOR DA REGIÃO SUDESTE DO CRÁTON AMAZÔNICO
}

\author{
CARLOS J.S. ALVARENGA* \& GERSON S. SAES**
}

\begin{abstract}
STRATIGRAPHY A>TOSEDIMENTOLOGY OF THE MIDDLE AND LATE PROTEROZOIC IN THE SOUTHEAST OF THE AMAZONIAN CRATON. The southeastern part of the Amazonian Craton is made up of Archean and Lower Proterozoic sequences including gneiss, greenstone belts and a huge granitic suite. During the Middle Proterozoic this craton was affected by an exteasional regime, during which fult zones of the cratonic basement were reactivated. Basins formed during this episode were nUed byte sediments of the Aguapei, Sunsás and Huanchaca groups. These sedimente are interpreted as the product of deposition as a platform cover, with extensive shallow marine by-passing to deeper marine deposition ends with fluvial sediments. In the Sunsás and Aguapef belt these middle Proterozoic sediments were affected by the Sonsas Orogeny, whereas in the Huanchaca, Santa Barbara and Rio Branco regions, they are spared of the deformation. Late Proterozoic sediments and metasediments are present along the trasition zone between the Amazonian Craton ande the Paraguay Belt.Three Major Glaciomarine sediments deposited on shelf domain (Puga Formation) and slope environments (Cuiabá Group). In this Last enviroment the glaciomarine sediments were strongly reworked by turbidites currents. The midle unit inclues Carbonate (Araras Formation) deposited directly on top of glaciomarine sediment, which the changes laterally towards the border of the Craton to muddy limestones (Guia Formation). The upper unit consists of siliciclastic sediments (Raizama and Diamantino formations).
\end{abstract}

Keywords: Stratigraphy, Mid-Late Proterozok, Paraguay Belt, Aguapef Group, Mato Grosso.

RESUMO 0 sudeste do Cráton Amazônico é formado por seqüências do Arqueano ao Proterozóico Inferior, que apresentam gnaisses, rochas verdes (greenstone belts) e suítes greníticas. Durante o Proterozóico Médio, a ruptura deste cráton se deu ao longo de zonas de fraquezas preexistentes originamk) bacias rojos Ikrátes são formados por falhas reativadas do embasamento. Essas bacias foram preenchidas petos sedimentos dos Grupos Aguapeí Sunsás e Huanchaca. A reconstrução paleogeográfica desses sedànentos, no Brasil, foi estabelecida como uma cobertura de plataforma iniciada por extensa sedimentação marinha rasa que passa a um anbiente marinho mais profundo, cuja sedimentação de caráter progradacional termin com a presença de depoóito sfluviais. Essas uniades são compostas principalmente por rochas nã o-metamôrficas nas regiõ es de Huanchaca, Santa Bárbara e Rio Branco. Nas Faixas do Proterozó ico Superior estão presentes ao longo da zona de transmição) entre o Crayon Amazônico e a Faixa Paraguai. Três unidades litoestratigrá ficas principais foram individualizadas, uma unidade cuja sedimentação foi interpretada como glá cio-marinha no domínioda plataforma (Formacão e Puga) e no domínio do talude foi caracterizada pelo forte retrabalhamento de sedimentos glácio-marinhos por correntes de turbidez (Grupo Cuiabá); uma unidade carbonatada pós-glacial, com calcários e dolomitos (Formação Araras), sobre a plataforma cratônica, que passa lateralmentẹ para calcarios mais argilosos (Formação Guia) em direção a zona mterna da faixa; a unidade superior (Formações Raizama e Diamantino) é formada por sedimentos siliciclásticos.

Palavras-chaves: Estratigrafia, Meso-Neoproterozóico, Faixa Paraguai, Grupo Aguapeí, Mato Grosso.

INTRODUÇÃO Neste trabalho é apresentada uma síntese geológica das unidades sedimentares e rnetassedirnentares do Proterozoico Médio é Superior que afloram na parte sudeste do Cráton Amazônico. Estas unidades têm sido descritas em várias áreas com diferentes denominações.

As coberturas sedimentares do Proterozoico Médio estão localizadas em várias sub-bacias espalhadas pelo embasamento cratônico consolidado há $1300 \mathrm{Ma}$ (Litherand et al. 1986) (Fig. 1). No Brasil, essas unidades foram denominadas de Águapeí (Figueiredo \& Olivattí 1974), enquanto em território boliviano são conhecidas pelo Chupo Huanchaca (Litherland \& Power 1989)naSerraHuanchaca e, na região de Santo Corazón, pelo Grupo Sunsás (Litherland et al. 1986). O Ciclo Orogenético Sunsás $(\sim 1.000 \mathrm{Ma})$ é o responsável pela deformação dessas rochas em duas faixas: Faixa Sunsás, na Bolívia, e Faixa Aguapef, no Brasil. Fora dessas duas faixas estreitas e alongadas, suas rochas apresentam-se como coberturas de plataforma não-deformadas nas Serras Huanchaca, Santa Bárbara e Monte Cristo, esta última na região de Rio Branco (Fig. 1).

No Proterozoico Superior, a Faixa Paraguai engloba os sedimentos e metassedimentos deformados pela tectônica bra- siliana (-600 Ma), individualizados em uma zona externa e outra interna, e os sedimentos suborizontalizados que se estendem para a zona de cobertura de plataforma cratônica (Fig. 1). Na primeira subdivisão estratigráfica para as rochas da Faixa Paraguai, foram individualizadas as Ardósias (filitos) Cuiabá, Calcários Araras e Arenitos Raizama (Evans 1894). Maciel (1959), Almeida (1964a, 1965) e Vieira (1965) estabeleceram novas unidades estraügráficas (Formação Puga, Grupo Jangada, Formação Bauxi, Formação Diamantino) cujos dados proporcionaram algumas hipóteses de correlações estratigráncas para o conjunto da Faixa Paraguai. As mais recentes sínteses estratígráficas e tectônicas englobando a faixa f oram propostas por Almeida (1984) e Alvarenga (1990).

Neste trabalho é feita uma revisão e discussão das correlações litoestratígráficas das unidades do Proterozoico Médio e Superior localizadas na borda sudeste do Cráton Amazônico, no Brasil e na Bolívia.

EMBASAMENTO O embasamento das coberturas sedimentares das Bacias Aguapeí-Sunsás, existentes na poção meridional do Cráton Amazônico, é formado por rochas cujas

\footnotetext{
* Departamento (k Geologia Geral, Umversidade Federal de Mato Grosso, CEP 78060-900, Cuiabá, MT, Brasil, Endereço atual: Departamento De Geologia Geral e Aplicada, Instituto de Geociências, Universidade de Brasília, CEP 70910-900, Brasília, DF, Brasil

** Departamento de Recursos Minerais, Instituto de Ciências Exatas e da Terra Universidade Federal de Mato Grosso, Cep78060-900, Cuiabá, MT, Brasil
} 


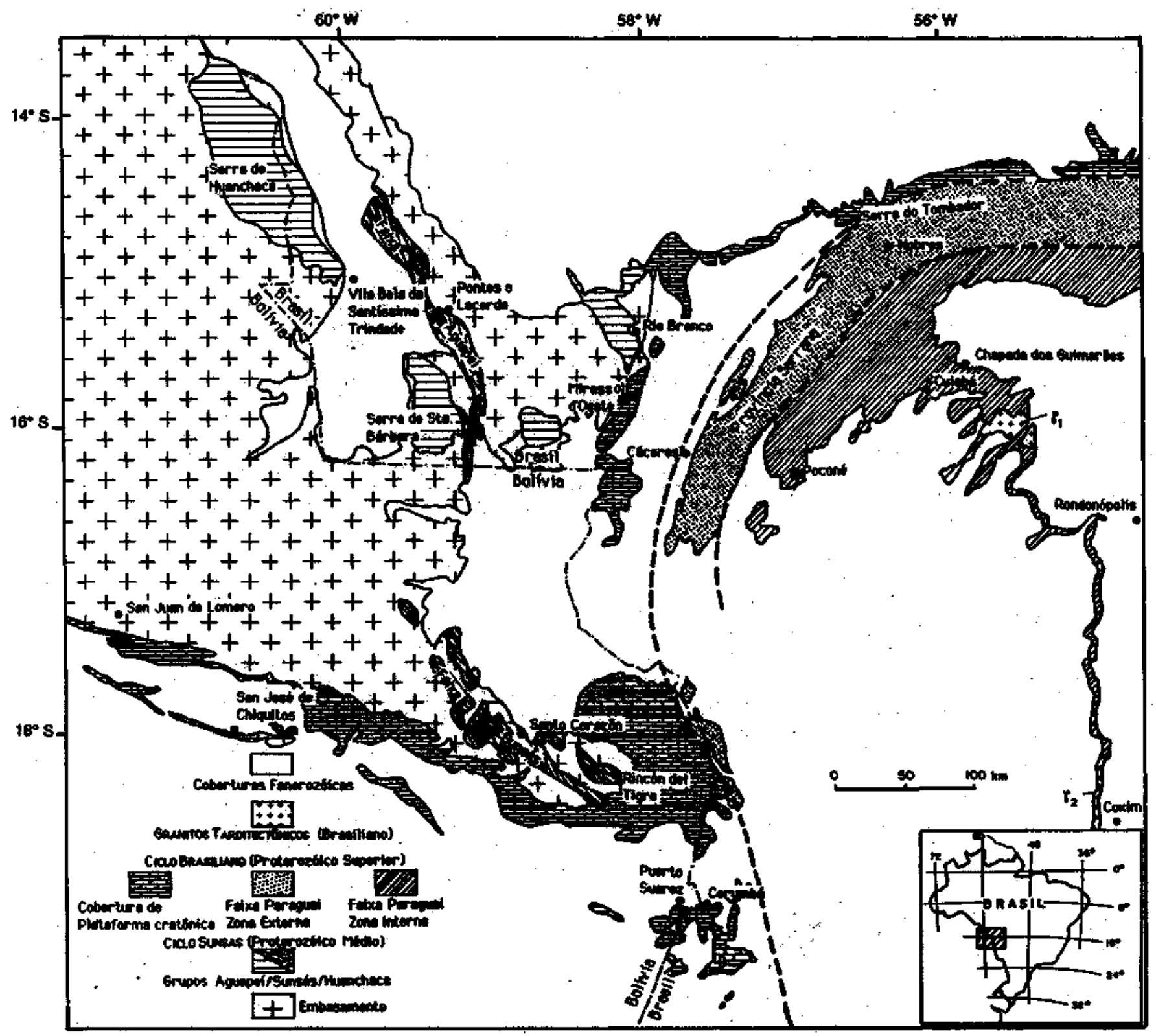

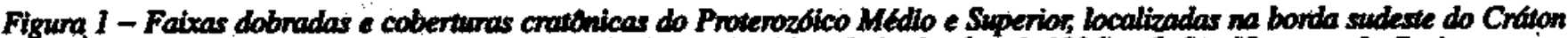
Amazonico (modificado de Bairos et al. 1982, Del'Arco et al. 1982 e Ltherland et al. 1986). Y1. Sta Vicente, $\gamma 2$. Catin

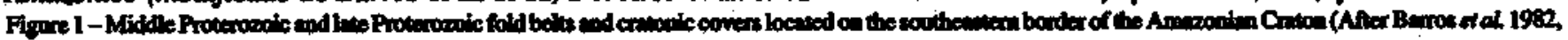

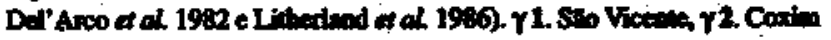

idades vão do Arqueano ao Protezóico Médio (1.300 Ma). Ao Arqueano estào reladonadc» o Complexo Gnáissico (Rio Vermelho) e os cinturões de rochas verdes (Rio Alegre, Quatro Meninas, Araputanga e Cabaçal) (Saes et al 1984, Monteiro et al 1986, Leite et al 1986, Leite 1987). O retrabalhamento parcial dessas unidades no Proterozóico Inferior deu origem a uma associação gnaisse-migmatftica denominada de Brigadeirinho (Saes et al. 1984). No Proterozóico Médio, processos metamórficos e deformacionais estão registrados no Complexo Granítico Santa Helena, seguidos por um magmatismo tardi a pós-cinemático representado pelos Granitóides Água Clara e Alvorada (1.500 Ma) (Monteiro et al 1986). Ao final do Proterozóico Médio (1.300 Ma), são alcançadas condições de estabilidade que propiciaram ò desenvolvimento de corpos máficos diferenciados (Suíte Intrusivá Rio Branco) e a individualização das Bacias Intracratônicas Aguapeí-Sunsás (Leite et al. 1985). Os lineamentos orientados N25-35W deste embasamento parecem ter exercido forte influência na estruturação das bacias do final do Proterozóico Médio, o mesmo acontecendo com a orientação das deformações das Faixas Sunsás e Aguapeí, que apresentam deformações coaxiais da orogênese precedente.

BACIA DO PROTEROZÓICO MÉDIO As coberturas sedimentares e metassedimentares predominantemente quartzftícas com alternâncias de fácies heterolítícas e cortadas por diques de rochas básicas, que ocorrem no Sudoeste de Mato Grosso e na Bolívia Oriental, foram pela primeira vez mencionadas em relatório da LASA (1968). Essas rochas foram posteriormente denominadas de Unidade Aguapeí por Figueiredo \& Olivattí (1974). Souza \& Hildred (1980) dividiram o Grupo Aguapeí nas Formações Fortuna, Vale da Promissão e Morro Cristalina, reconhecendo o desenvolvimento de uma seqüência marinha transgressivo-regressiva de cobertura de plataforma, Saes et al (1987) e Takahashi et al (1990) documentaram as fácies sedimentares do Grupo Aguapeí nas 
regiões de Rio Branco e Pontes e Lacerda, respectivamente, detalhando e estabelecendo modelos de fades para as formações propostas por Souza \& Hildred (1980). Na parte oriental da Bolívia, os trabalhos de mapeamento regional levaram ao estabelecimento de uma área cratônica (Cráton Paraguá) circunscrita pelas Faixas Móveis Sunsás e Aguapeí (Litheriand et al 1956).

Formação Fortuna A Formação Fortuna é a unidade basal formada por arenitos e conglomerados ortoquartzíticos. A figura 2 mostra as correlações litoestratigráficas entre a unidade basal tanto no Brasil como na Bolivia. No oriente boliviano, a Formação Fortuna corresponde à Lower Psamitic Unit (Litheriand \& Bloomfield 1981) e à Formação Arco íris (Litheriand \& Power 1989) sendo formada por um pacote de arenitos e conglomerados ortoquartzíticos, com notável aumento de espessura e do conteúdo de feldspatos de noroeste para sudeste em direção a Santo Corazón (Fig. 2). A natureza areno-conglomerática, com abundantes estratificapões cruzadas

revela deposição em sistemas fluviais entrelaçados nas áreas das Serras de Huanchaca e São Vicente, passando a plataforma marinha rasa com influência de marés, leques costeiros (fandeltas) e tempestitos em Pontes e Lacerda e Rio Branco. As áreas mais a sul, na região de Santo Corazón, podem incorporar espessos sistemas de leques aluviais ou costeiros, como resultado da expressiva atuação de falhas sin-sedimentares. A bipolaridade das paleocorrcntes (NW-SE), na região de Pontes e Lacerda e Rio Branco, reforça a hipótese de sedimentação por ação de marés, bem como sugere o preenchimento longitudinal de uma bacia alongada nesta direcão desde os primórdios de sua instalação (Litheriand et al 1986, Saes et al 1987, Litheriand \& Power 1989, Saes \& Leite no prelo).

Formação Vale da Promissão A Formação Vale da Promissâo representa uma cunha de sedimentos marinhos progradante, espessando-se para SE. Nas regiões de Rio Brancoe Pontes e Lacerda, ela é compôs tá por pelitos com intercalações arenosas depositadas por ação de tempestades em uma plataforma marinha rasa (Saes et al 19IT7). Em direção a Santo Corazón, a Formação Vale da Promissão passa a seqüências turbidíticas (Litheriand et al. 1986). Ela corresponde à Argillaceous Unit de Litheriand \& Bloomfield (1981) e eventualmente à Formação Cuatro Carpas (Litheriand \& Power 1989) da Serra de Huanchaca, onde a interestratificação de lobos arenosos e pelitos sugere a existência de construções deltaicas. Essa unidade sedimentar intermediária dos Grupos Aguapei/Sunsás foi sedimentada após o clímax da transgressão marinha regional que marca este intervalo, representando uma progradação com alto nível do mar.

Formação Morro Cristalina A Formação Morro Cristalina e formada de quartzo-arenitos e mais raramente conglomerados, cujos principais atributos sedimentológicos são a maturidade elevada e 0 caráter exclusivamente continental (fluvial e eólico) de seus depósitos (Saes et al. 1987, Litheriand $\&$ Power 1989). Digno de nota é o fato desta unidade ocorrer apenas nos setores nâo-deformados dessas bacias, o que, conjugado ao predomínio de paleooorrentes fluindo de SE para NW, parece indicar que a sua deposição ocorreu após a principal f ase deformacional que afetou estas coberturas e a inversão do paleodeclivê regional para NW, o que sugere um caráter molassóide para a sua sedimentação. Essa coluna arenosa superior recebe a denominacão de Upper Psamitic Unit em Santo Corazón (Litheriand et al 1986), sendo duvidosamente correlacionada à Formacão Buena 'Vista na Serra de Huanchaca (Litheriand \& Power 1989).

BACIA DO PROTEROZÓICO SUPERIOR As unidades litoestratigráficas do Proterozóico Superior que se desenvolveram na borda sudeste do Cráton. Amazônico se apresentam dentro de domínios tectono-estratigráficos que

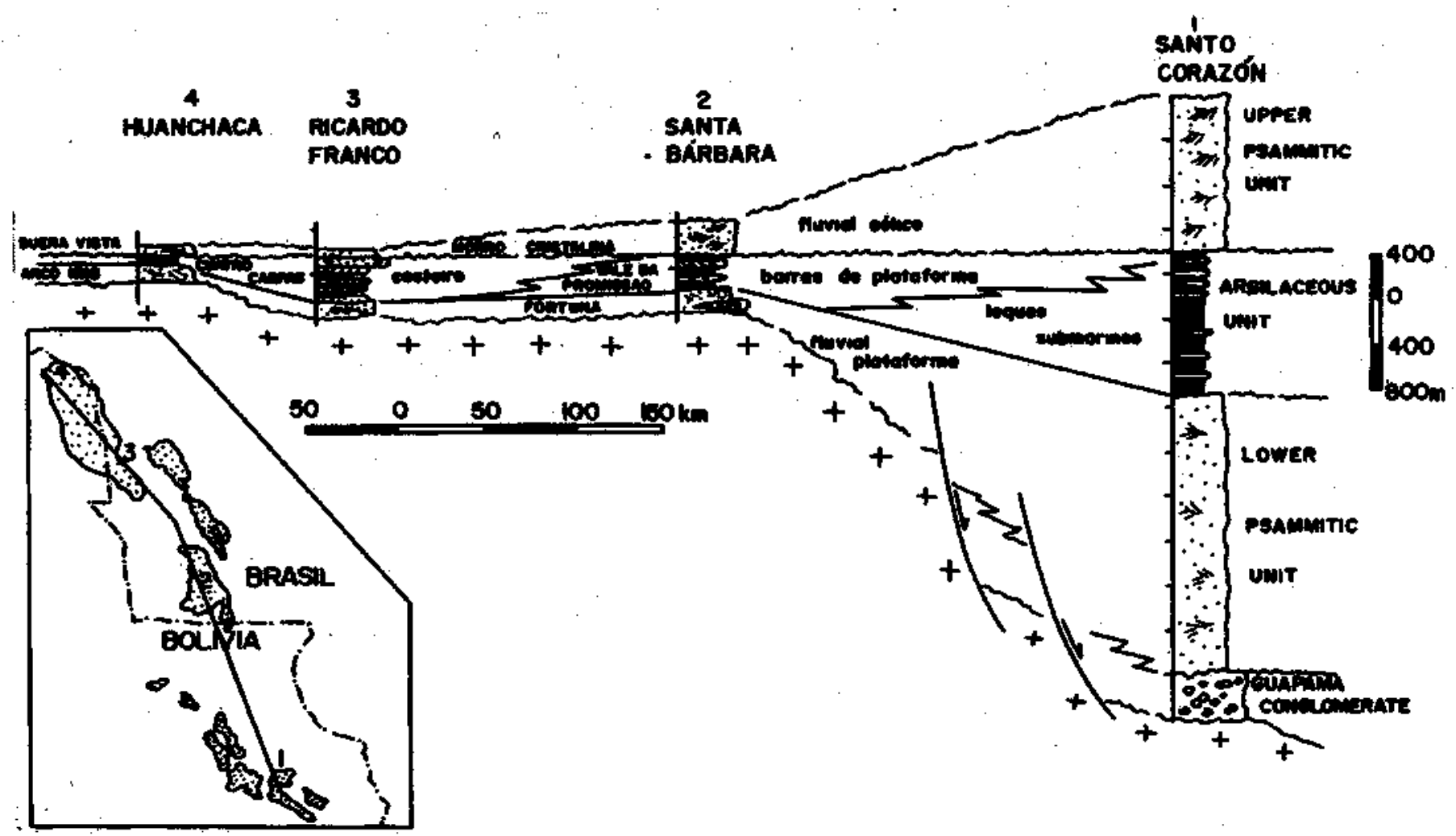

Figura 2 - Correlações litoestratigráficas entre as bacias sedunentares do Proterozóico Médio da borda sudeste do Cráton Amazônico

Figure 2 - Lithoestratigraphic relationships between Middle Proterozoic sediinentaiy basins on the border of the Aniazoniancn^ 
gradam lateralmente de coberturas suborizontais de plataforma, para rochas dobradas e parcialmente metamorfizadas para o interior da Faixa Paraguai (Almeida1984, Alvarenga 1990). O reconhecimento da influência da última glaciação do Proterozóico Superior em diferentes unidades litoestratígráficas dessa região permitiu a sua correlação estratigráfica em diferentes domínios dentro da bacia de sedimentação.

As diferentes colunas estratigráficas propostas para a Faixa Paraguai apresentam controvérsias na passagem entre as zonas estruturais interna e externa da faixa (Alvarenga 1984). Por causa dessa discordância, duas interpretações estratigráficas foram propostas para esta zona de transição:

1. Presença de duas grandes unidades estruturais e estratigráficas, onde as rochas da zona interna (Grupo Cuiabá), mais fortemente metamorfizadas e dobradas, são consideradas como mais antigas que aquelas das Formações Diamantino, Raizama, Araras, Puga e Bauxi que formam a zona externa da faixa e a cobertura cratônica (Figueiredo \& Olivatti 1974, Ribeiro \& Figueiredo 1974, Ribeiro et al. 1975, Luz et al. 1978, 1980, Schobbenhaus et al 1981,1984, Barros et al. 1982, Del'Arco et al 1982, Almeida 1984).

2. Depósitos parcialmente contemporâneos entre as rochas sedimentares que formam a parte inferior da cobertura de plataforma e da zona externa da faixa (Formações Puga e Bauxi) e os metassedimentos da zona interna da faixa de dobramentos (Chupo Cuiabá) (Almeida 1964a,b, 1965,1974, Alvarenga 1985,1988, Alvarenga \& Trompette 1988,1992). As rochas sedimentares, levemente dobradas na borda externa da Faixa Paraguai, passam lateralmente às coberturas de plataforma do Cráton Amazônico. A maioria das unidades ütoestratigráficas se distribuí através de diferentes faties, nos Ires domínios estruturais individualizados. Assim, por exemplo, a unidade estratigráfica que inclui as Formações Puga e Bauxi é pouco espessa e subonzontal na zona de cobertura cratônica, passando a uma unidade litoestratigráfica um pouco mais espessa e dobrada, dentro da zona externa da faixa. No domínio interno da faixa, esta unidade inclui o Grupo Cuiabá, espesso, tectonizado e metamorfizado (Alvarenga 1988, Alvarenga \& Trompette 1988,1992).

As unidades estratigráficas utilizadas neste trabalho, de acordo com a tese de contemporaneidade entre as rochas da cobertura de plataforma e das faixas dobradas, foram reunidas em quatro grandes grupos, formados por diferentes faties (Alvarenga 1988,1990): 1. unidade inferior, de caráter local e situada a NW da Cidade de Poconé no núcleo da Anticlinal de Bento Gomes, é composta por filitos, filitos grafitosos, quartzitos e dolomites; 2. extensa unidade glátio-marinha/turbidítica foi formada durante a ultima glaciação do Proterozóico Superior, 3. espessa unidade carbonatada; 4. unidade superior detrítica (Fig. 3).

Unidade Inferior A unidade inferior está representada apenas por parte das rochas do Grupo Cuiabá (zona interna da faixa), situada no núcleo da Anticlinal de Bento Gomes a noroeste de Poconé (Fig.l). Nesta unidade, está incluída a maioria das rochas grafitosas (filitos e quartzitos) do Grupo Cuiabá, que localmente estão associadas a dolomites. Esta unidade foi estratigrafícamente individualizada por Luz et al (1980), nas subunidades 1e 2 do Chupo Cuiabá.

Unidade glácio-marinha-turbidítica Esta unidade foi estudada para a região entre Cuiabá-Província SerranaMirassol d'Oeste, entretanto, correlações estratigráficas foram feitas com as regiões de Corumbá e da Bolívia.

REGIÃO DE CUIABÁ-PROVÍNCIA SERRANA-MIRASSOL $D^{\prime} O E S T E$ Esta unidade inclui todas as rochas formadas durante o último período glacial dp Proterozóico Superior, incluindo as rochas formadas pela influência direta de uma sedimentação glátio-marinha e também as formadas em ambience marinho mais distai, originadas de materiais glaciogênicos retrabalhados por correntes turbidíticas.

As rochas das Formações Puga, Bauxi e da maioria do Grupo Cuiabá formam a unidade glátio-marinha e turbidítica do Proterozóico Superior da região. As variações de faties laterais e verticais entre diamictitos, argilitos, siltitos, quartzitos e conglomerados sugerem a passagem de um ambiente gláciomarinho de plataforma, a oeste, para uma batia turbidítica, a teste (Fig. 3).

Na zona de cobertura cratônica, os afloramentos da unidade glátio-marinha se reúnem na Formação Puga. Eles são compostos de diamictitos, com intercalações de arenitos finos e siltitos depositados em discordância angular sobre o embasamento do Cráton Amazônico.

$\mathrm{Na}$ zona externa da faixa, diamictitos maciços e estratificados formam a litologia predominante da Formação Puga que constitui a unidade glácio-marinha dessa zona (Alvarenga 1988, Alvarenga \& Trompette 1988,1992). Importantes intercalações de arenitos, contendo ocasionalmente seixos e blocos isolados (Formação Bauxi), são conhecidas nas regiões entre Bauxi e Nobres (Fig. 1 e 3). Essas intercalações arenosas, inicialmente denominadas de Formação Bauxi, são na realidade uma faties arenosa da Formação Puga.

$\mathrm{Na}$ zona interna da faixa, os metassedimentos dobrados e metamorfizados, denominados de "Brasilides metamórficas" por Almeida (1984,1985), são principalmente compostos pelas rochas do Grupo Cuiabá. Estas rochas foram depositadas durante um período glacial, incluindo ambiente glácio-marinho sobre a plataforma cratônica e turbidítico no domínio do talude e no talude distai (Alvarenga 1988,1990, Alvarenga \& Trompette 1988,1992) que caracterizam a zona interna da faixa.

Três grandes grupos de faties sedimentares, com base nas suas características de sedimentação turbidítica proximal, intermediária e distai, configuram a sedimentação no talude da bacia (Fig. 3).

Na parte superior do talude (fácies proximal), são encontrados diamictitos intercalados a conglomerados e arenitos. Esta área é parcialmente coincidente com a região considerada por Almeida (1974) como pertencente ao Grupo Jangada e com as áreas mapeadas como subunidades 4,5 e 7 do Grupo Cuiabá descritas por Luz et al. (1980).

Em direção às partes mais externas do talude, os filitos apresentam espessas intercalações de quartzitos, quartzitos conglomeráticos e metaconglomerados, de até $100 \mathrm{~m}$ de espessura, que são internamente organizados em ciclos de granodecrescência para o topo. Estas intercalações (quartzitos e conglomerados) foram interpretadas por Alvarenga (1985) como leques de alimentação de uma fácies turbidítica grossa. Os afloramentos dessa fácies estão incluídos na área mapeada por Luz et al (1980) como subunidades 3 e parte da 5 do Grupo Cuiabá.

Nas porções externas do talude e em direção ao extremo teste da bacia, uma faties mais distai é composta quase que exclusivamente por filitos, podendo apresentar intercalações mais grossas formadas internamente por vários ciclos gradacionais de quartzitos e metassiltitos. Os filitos desta fácies são pouco conhecidos, por se encontrarem quase que totalmente capeados por formações superficiais ou por se apresentarem bastante alterados.

Seixos e blocos de natureza diversa são encontrados de forma isolada e cortando a estratificação dos metassedimentos. Estes são provavelmente transportados por icebergs e são a única indicação direta da presença da glaciação.

REGIÃO DE CORUMBÁ E DA BOLÍVIA ORIENTAL As coberturas de plataforma cratônica da região de Corumbá estendem-se para oeste, em território boliviano (Fig. 1). Has foram depositadas sob domínio cratônico, que foi afetado por uma tectônica rígida de falhas isolando blocos mais ou menos elevados, como é o caso do Morro de Urucum, próximo a Corumbá. 


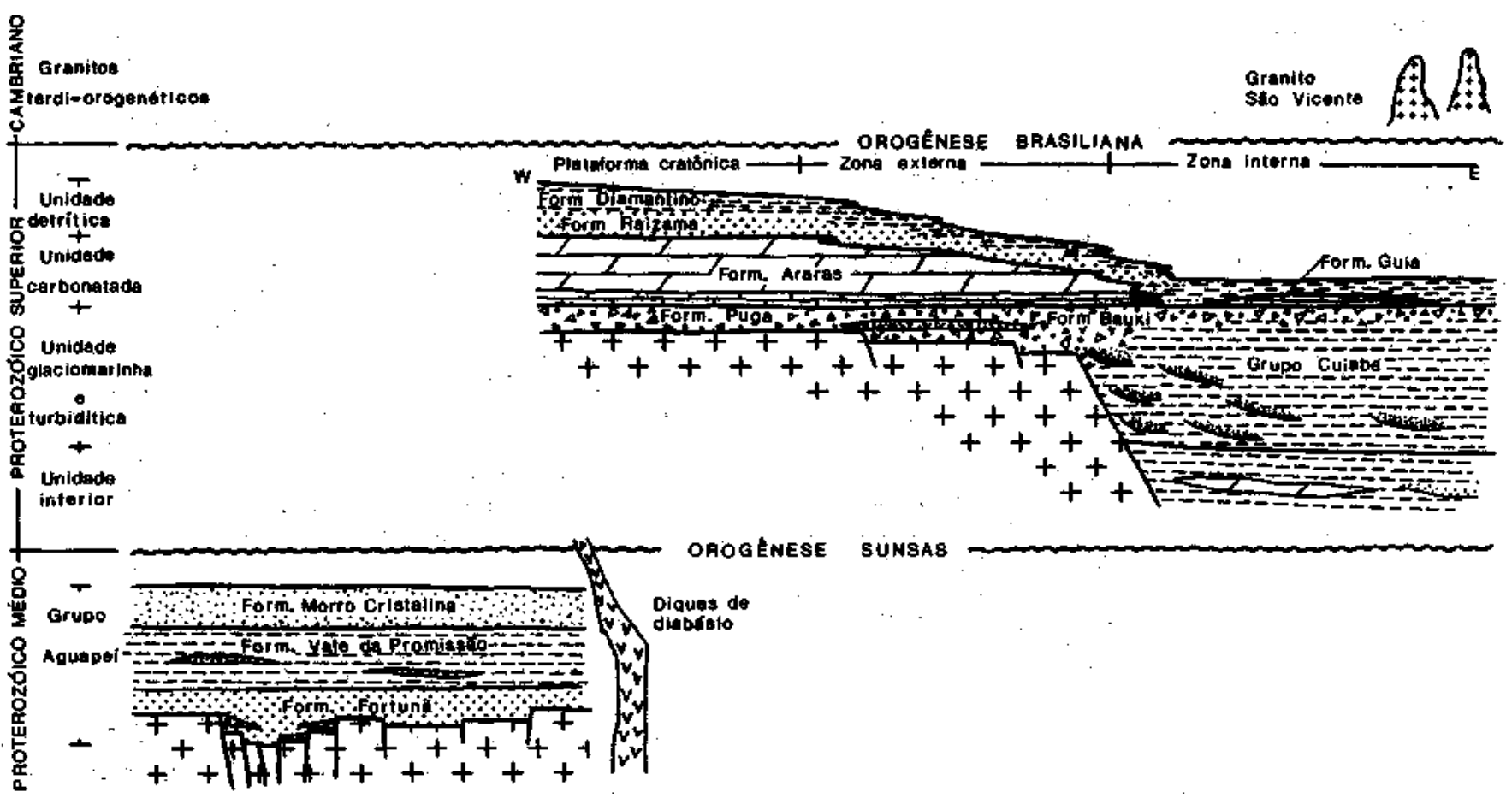

Figura 3 - Esquema das relações estratigráficas dá Pwterozóico Médio e Superior na borda sudeste do Cráton Amazônico (sem escala)

Figure 3 - Middle Proterozoic and Late Proterozoic schematic stratigraphic relationships on the border of the Amazonian craton (not to scale)

A unidade inferior aflorando ao sul da Faixa Sunsás até as proximidades de Corumbá é formada pelos Grupos Boqui e Jacadigo e pela Formação Puga.

O Grupo Boqui engloba arcósios, conglomerados, arenitos, siltitos, calcários e diamictitos e apresenta importantes variações laterais de fácies (Litherland et al. 1986).

O Grupo Jacadigo, considerado como depositado dentro de uma bacia marginal cratonica (Almeida 1984), foi subdividido em duas formações: Formação Urucum, basal, composta de arcósios e conglomerados com blocos e seixos do embasamento, e Formação Santa Cruz, composta de finas alternâncias de jaspilitos é arcósios e incluindo camadas manganesíféras que localmente podem atingir $5,4 \mathrm{~m}$ na porção inferior da formação. Gastos caídos (dropstones) de granito foram identificados nesta formação.

A Formação Puga é composta de diamictitos com intercalações arenosas e reconhecida como uma fácies glacial (Maciel 1959).

Unidade carbonatada A unidade carbonatada é formada na região de Cuiabá pela Formação Araras e em Corumbá e Bolívia Oriental pelos Grupos Corumbá e Muciélago, respectivamente.

REGIÃO DE CUIABÁ Os calcários e dolomites da Formação Araras têm suas melhores exposições na zona de cobertura cratonica e na zona externa da faixa. Nessa última eles atingem uma espessura de até $1.300 \mathrm{~m}$ (Luz et al. 1978). Um membro inferior de $200 \mathrm{~m}$ é formado de calcários e calcários margosos cinza-escuros. Os $1.100 \mathrm{~m}$ restantes do membro superior, são formados por dolomitos bem cristalizados cinzas e brancos. Nos dolomitos da zona de cobertura cratonica, foi descrito por Zaine (1991) um nível estratiforme e colunar de estromatólito limitado na base e no topo por cama* das de evaporitos (pseudomorfos), indicando evidências de salinidade variável durante a deposição. Estromatólitos colunares, intraclastos e níveis de calcarenitos com laminação cruzada são encontradas em direção ao topo da Formação
Araras, sugerindo um aumento da energia do ambiente. Intercalações arenosas são também encontradas no topo da formação que termina com o início da sedimentação detrítica da Formação Raizama.

$\mathrm{Na}$ zona interna, esta unidade é correlacionada à parte superior da seqüência metassedimentar do Grupo Cuiabá, formada por uma fácies pelito-carbonatada denominada de Formação Guia (Fig. 3) (Alvarenga 1988) ou subunidade 8 (Luz et al. 1980). Na Sinclinal da Guia, essa fácies é composta de calcários, calcários margosos e lentes dolomíticas que passam a metassiltitos e metargilitos laminados (Alvarenga 1990).

REGIÃO DE CORUMBÁ E BOLÍVIA ORIENTAL A unidade carbonatada é formada pelas rochas que foram reagrupadas no Grupo Corumbá (Formações Bocaina e Tamego) em território brasileiro e no Grupo Muciélago na Bolívia.

Unidade superior A unidade superior é composta por uma espessa seqüência de rochas détríticas, compreendendo os arenitos feldspáücos da Formação Raizama e os argilitos, siltitos e arcósios da Formação Diamantino, todas as duas reunidas no Grupo Alto Paraguai (Fig. 3). Essa unidade tem suas exposições na zona de cobertura cratonica e na zona externa da faixa. A Unidade Superior não foi encontrada na região de Corumbá. Arenitos (Formação Mandioré) depositados sobre os calcários (Grupo Muciélago) são descritos em território boliviano (Litherland et al. 1986) e podem ser o equivalente boliviano da Formação Raizama.

CONCLUSÕES As rochas détríticas do Proterozóico Médio da borda sudeste do Cráton Amazônico se depositaram em bacias moldadas por grandes falhas do embasamento. $\mathrm{O}$ seu preenchimento está relacionado a período de prolongada estabilidade tectônica, não se descartando a possibilidade de atuação de falhas sinsedimentares. As diferentes fácies associadas às variações na sua espessura e ao padrão de paleocorrentes das rochas do Grupo Aguapeí sugerem que a sedimentação iniciouse por uma invasão marinha rasa (Formação Fortuna), passan- 
do a uma sedimentação progradante com nível de mar alto (Formação Vale da Promissão) e, finalmente, a uma sedimentação fluvial de domínio continental '(Formação Morro Cristalina). Uma espessa coluna estratigráfica, com a presença de arcósios e uma significativa importância de conglomerados, ao longo das duas faixas dobradas (Sunsás e Águapeí), sugere serem elas duas sub-bacias localizadas em zonas de fraquezas crustais do embasamento com falhas que atuaram também durante a sedimentação, causando a sua maior subsidência quando comparadas com as colunas estratígráficas menos espessas das sub-bacias adjacentes (Fig. 2). Essas duas bacias mais profundas coincidentemente são as únicas que foram posteriormente dobradas pela Orogênese Sunsás ( 1.000 Ma). No Proterozóico Superior, três unidades litoestratigráficas principais foram individualizadas sobre as coberturas cratônicas da borda SE do Cráton Amazônico e no interior da Faixa Paraguai. Uma unidade basal restrita a faixa dobrada é observada na região ao Anticlinório de Bento Gomes à noroeste de Poconé. A unidade glácio-marinha/turbidftica é contemporânea à glaciação do final do Proterozóico Superior que influenciou mais de perto os sedimentos glácio-marinhos da plataforma continental, que foram a fonte do material transportado como fluxo de débitos (debris-flow) e turbiditos depositados do talude em direção ao interior da bacia. À influência do período glacial é mais facilmente detectada nos sedimentos de cobertura de plataforma (glácio-marinhos) e parcialmente retrabalhados por fluxos de gravidade. Na zona interna da faixa, os sedimentos foram originalmente depositados em uma bacia marginal desenvolvida na quebra da plataforma continental

ALMEIDA, F.F.M. 1964a. Geologia do Centro-Oeste Matogrossense. Rio de Janeiro. DNPM/DGM. 13? p. (Boletim 215).

ALMEIDA, F.F.M. 1964b. Glaciação Eo-Cambriana em Mato Grosso. Rio de Janeiro, DNPM/NPE. 10 p. (Boletim 117).

ALMEIDA,F.F.M. 1\%5.Geossinclínco Paraguaio. In: SEMANA DE DEBATES GEOLÓGICOS, I. Porto Alegre, 196S. Porto Alegre, Centro Acad. Est GeoL, UFRGS. p. 87-101.

ALMEIDA, F.F.M. 1974. Sistema tectônico marginal do Cráton do Guaporé. In: CONOR. BRAS. GEOL., 28. Porto Alegre, 1974. A/W/J... Porto Alegre, SBG. v. 4, p. 11-17.

ALMEIDA, F.F.M. 1984. Província Tocantins-setor sudoeste. In: ALMEIDA, F.F.M. \& HASULY. eds. O Pré-Cambriano do Brasil. São Paulo, Ed. Blücher. p. 265-281.

ALMEIDA, F.F.M. 1985. Alguns problemas das relações geológicas entre o Cráton Amazônico e as faixas de dobramentos marginais a leste. In: SIMP. GEOL. CENTRO-OESTE, 2. Goiânia, 1986. Atas... Goiânia, SBG. p. 314.

ALVARENGA, C.J.S. 1984. Dobramentos da Fạixa Paraguai na borda sudeste do Cráton Amazônico. In: CONGR. BRÁS. GEOL., 33. Rio de Janeiro, 1984. Anais... Rio de Janeiro, SBG. v. 7, p. 3258-3271.

ALVARENGA, CJ.S. 1985. Evidências de fácies turbidíticas grosseiras no Grupo Cuiabá, MT. In: SIMP. GEOL. CENTRO-OESTE, 2. Goiânia, 1985. Atas... Goiânia, SBG. p. 256-266.

ALVARENGA, C J.S. 1988. Turbiditos e a Glaciação do final do Proterozóico Superior no Cinturão Paraguai, Mato Grossa Rev. Bras. Geoc., 18(3):323-327.

ALVARENGA, CJ.S. 1990. Phénomenes Sédúnentaires, Structuraux et Circulation de Fluides Développés à la Transition Chane-Craton: Example de la Quote Paraguai d'age Proterozoque Supérieur, Mato Grosso, Brésil. Marseille. 177 p. (These Doc. Sei. Univ. d'Aix Marseille HI).

ALVARENGA, C J.S. \& TROMPETTE, R. 1988. Upper Proterozoic glacial environment ofthe border of Amazonian Craton and its evolution towards the adjacent Paraguay Belt (Mato Grosso, Brazil). In: Meeting Earth's Glacial Record - Proj. 260. Cuiabá 1988. Abstracts and Field Trip... Cuiabá, IGCP-UNESCO/UFMT. p. 31-44.

ALVARENGA, CJ.S. \& TROMPETTE, R. 1992. Glacial influenced sedimentation in the uppermost Proterozoic and lower Cambrian of the Paraguay belt (Mato Grosso, Brazil). Palaeogeogr. PalaeoclimatoL PalaeoecoL, 92:85-105.

BARROS, A.M.; SILVA, R.M.; CARDOSO, O.R.F.A.; FREIRE, F.A.; SOUZA, J J., Jr.; RIVETTI. M., LUZ, D.S.; PALMEIRA, R.C.B.; TASSINARI, C.C.G. 1982. Folha SD21 Cuiabá, Geologia. In: RADAMBRASIL. Levantamento de Recursos Naturais. Rio de Janeiro, Radambrasil. p. 25-192. (Volume 26).

DEL'ARCO, J.O.; SILVA, R.H.; TARAPANOFF, L; FREIRE, F.A.; PEREIRA, L.G.M.; SOUZA, S.L.; LUZ, L.G.; PALMEIRA, R.C.B.; (zona do talude), com domínio de uma sedimentação por fluxos gravitacionais. Ao término ao período glacial, supõem-se que todos os detritos retidos nas geleiras tenham sido derretidos, gerando assim um grande aporte de sedimentos para o interior da bacia. Nesse caso, esses sedimentos do final da glaciação poetem explicar a extensão de diamictitos por toda a bacia da Formação Puga ao Grupo Cuiabá no interior da zona interna (Fig. 3). A unidade carbonatada marca o inicio da sedimentação devido ao aumento do nível do mar. Os calcários escuros e laminados da base dessa unidade passam no topo a dolomite (dolarenitos) que se intercalam com sedimentos detríticos arenosos. Esses carbonates (Formacão Araras) caracterizam uma sedimentação de plataforma marinha rasa, em regime de deposição progradacional, culminando com a sedimentação dos arenitos da unidade superior (Formação Raizama). No interior da bacia, a unidade detrítica superior pode ter seu correspondente nos metassiltitos e metargilitos laminados do Grupo Cuiabá que se encontram acima da unidade carbonatada (Formação Guia).

Agradecimentos Os autores agradecem o apoio financeiro e científico proporcionado pela UFMT, PADCT e CNPq (Proc. 40.7171/83, 403469/89-9 e 500647/90-9). Agradecemos também aos organizadores da conferência de campo sobre o Proterozóico Médio e Superior no Brasil - A. J. Dourado Rocha e J. M. Landim Dominguez - a CPRM e a SBG por tomarem viável este evento. Um especial agradecimento a Roland Trompette, pelo incentivo, discussões e críticas na realização dos trabalhos sobre a Faixa Paraguai.

TASSINARI.C.C.G. 1982. Folha SE. 21 Corumbá e parte da Folha SE. 20. In: RADAMBRASIL. Rio de Janeiro, Radambrasil. p. 25-160. (Levantamento de Recursos Naturais 27)

EVANS, J.W. 1894. The geology of Mato Grosso. GeoL Soe. Lona., Quat. J., 50:85-104.

FIGUEIREDO, AJA. \& OUVATTI, 0.1974. Projeto Alto Guaporé. Goiânia, DNPM/CPRM. v. l, 173 p. (Relatório Final Integrado).

LASA - ENGENHARIA E PROSPECÇÕES S/A 1968. Levantamento Fotogeológico do Centro-Oeste de Mato Grosso. Rio de Janeiro, Lasa. 77 p. (Relatório 153).

LEITE, J.A.D. 1987. Integrated attempt of geological aspects of east Bolivia and southwest portion of Mato Grosso state, Brazil. In: MEETING PROJ. 204. Carajás, 1987. Extended Abstr... Carajás, IGCP-UNESCO. p. 113-115.

LEITE, J.A.D.; SAES, G.S.; RUIZ, A.S. 1986. Seqüências supracrustais do tipo Greestone Belts na porcão sul do Cráton Amazônico, Mato Grosso. In: CONGR. BRÁS. GEOL., 34. Goiânia, 1986. BoL Resumos.. Goiânia, SBG. p. 98.

LEITE, J.A.D.; SAES, G.S.; WESKA, R.K. 1985. A Suíte Intrusiva Rio Branco e o Grupo Aguapeí na Serra do Rio Branco, Mato grosso. In: SIMP. GEOL. CENTRO-OESTE, 2. Goiânia, 1985. Atas ... Goiânia, SBG. p. 247-255.

LTTHERLAND, M.; ANNELLS, R.N.; APPLETON JJX; BERRANGÉ, JJA; BLOOMFffiLD, K.; BURTON, C.CJ., DARBYSHIRE, D.P.F.; FLETCHER, CJJí; HAWKINS, MJ>; KLINCK, B.A.; LLANOS. A.; MITCHELL, W. L; O'CONNOR, E.A.; PITFIELD, REJ.; POWER, G.; WEEB, B.C 1986. The Geology and Mineral Resources of the Bolivian Precambrian Shield. London, Brit Geol. Surv. 153 p. (Overseas Memoir 9).

LTTHERLAND, M. \& BLOOMFELD, K. 1981. The Proterozoic History of Eastern Bolivia. Precamb. Res., 15:157-179.

LrTHERLAND, M. \& POWER, G. 1989. The geologic andgeomorphologic evolution of Serrania Huanchaca, eastern Bolivia: the legendary "tost workT. J. S. Am. E. Sci., 2:1-17.

LUZ, J.S.; OLIVEIRA, A.M.; LEMOS, D.B.; ARGOLO, J.L.; SOUZA, N.B.; ABREU FILHO, W. 1978. Projeto Província Serrana. Goiânia, DNPM/ CPRM. v. l, 105 p. (Relatório Final).

LUZ, J.S.; OLIVEIRA A.M.; SOUZA, J.O.; MOTTA JJIM.; TANNO, L.C. CARMO, L.S.; SOUZA, N.B. 1980. Projeto Coxipó. Goiânia, DNPM/ CPRM. v. l, 136 p. (Relatório Final).

MACIEL, P. 1959. Tllito Cambríano (?) no Estado de Mato Grosso. S3o Pauto, SBG. p. 3-49. (Boletim 8).

MONTEIRO, H.; MACEDO, P.M.; SILVA, M.D.; MORAES, A.A.; MARCHETTO, C.M.L. 1986 O Greenstone Belt do Alto Jauru. In: CONGR. BRÁS. GEOL., 35. Goiânia, 1986. Anais... Goiânia, SBG. v. 2 , p. 630-647. 
RIBEIRO, W., F \& FIGUEIREDO, AJA. 1974. Reconhecimento geológico da região oeste de Mato Grosso. In: CONGR. BRÁS. GEOL.,. 28. Porto Alegre, 1974. Anais... Porto Alegre, SBG. v. 4, p. 27-35.

RIBEIRO, W., F»; LUZ, J.S.; ABREU, W., R 197S. Projeto Serra Azul. Goiânia, DNPMO $>$ RM. v. I, 104 p. (Relatório Final).

SAK,G.S.;ALVARF^GA,CJ.S.;CUNHA,J.E1987.Depositosdeplataforma marinha dominada por marés e tempestades do Proterozóico Médio na porcão sudeste do craton amazônico, região de Rio Branco, MT. Ia: SIMP. SOBRE SISTEMAS DEPOSICIONAIS NO PRÉ-CAMBRIANO. OURO Preto, 1987. Amis... Ouro Preto, SBG/NMG. v. 6,1-15.

SAES, G.S. \& LEITE, J.A.D. (no prelo). Evolução tectono-sedimentar do Grupo Aguapeí: Mato Grosso e oriente boliviano. Rev. Bros. Geoc., (no prelo).

SAES, G.S.; LEITE, J.A.D.; WESKA, R.K. 1984. Geologia da Folha Jauru (SD-21-Y-C-ffl): Uma síntese dos conhecimentos. In: CONGR. SOC. BRÁS. GEOL., 33. Rio de Janeiro, 1984. Anais... Rio de Janeiro, SBG. v. 3, p. 2193-2204.

SOUZA, E.P. \& MILDRED, P.R. 1980. Contribuição ao estudo da geologia do Grupo Aguapeí, oeste de Mato Grosso. In: CONGR. BRÁS. GEOL., 31. Camboriú, 1980. Anais... Cambaria, SBG. v. 2, p. 813-825.

SCHOBBENHAUS, C, F*; CAMPOS, D.A.: DERZE, G.R.; ASMUS, H.E. 19\%1. Mapa Geológico do Brasil e da Area Oceânica Adjacente Incluindo Depósitos Minerais. Brasilia, DNPM. (Escala 1/2 500 000).
SCHOBBENHAUS, C, P; CAMPOS, DA.; DERZE, G.R.; ASMUS, H.E 1984. Geologia do Brasil Texto Explicativo do Mapa Geológico do Brasil e da Area Oceânica Adjacente Incluindo Depósitos Minerais. Brasília, DNPM. 501 p.

TAKAHASHI, A.T.; SILVA, P.C.S.; MENEZES, R.G. 1990. Aspectos dos ambientes de deposição do Grupo Aguapef na área da Falha Pontes e Lacerda (SD-Z1-Y-C-11). In: CONGR. BRÁS. GEOL., 36. Natal, 1990. Anais... Natal, SBG. v. I, p. 290-299.

VIEIRA, AJ. 1965. Geologia do Centro-Oeste de Mato Grosso. Petrobrás/ DEBSP. 58 p. (Relatório Técnico 303).

ZAINE, M.F. 1991. Análise dos Fósseis de Parte da Faixa Paraguai (MS, MT) e seu Contexto Temporal e PaUoambiental Sip Paulo. 215 p. (Tese Doutoramento, IG/USP).
MANUSCRITO A736

Recebido em 12 de maio de 1992 Revisão do autor em 15 de agosto de 1992 Revisio aceita «m 24 de agosto de 1992 